Predictors of repeat users were measured in a matched case-control study by conditional logistic regression analysis. A case $(\mathrm{N}=304)$ was defined as reporting having ever used IWTK before. A control was a user who reported never using the program earlier. Two controls $(\mathrm{N}=608)$ were systematically sampled for each case by matching date of use of IWTK of the case within 3 months.

Results From 2007 to 2010, 17\% of 1747 women who used IWTK for STI testing indicated they had used IWTK previously. Of these, $45 \%$ used it $>2$ times. Mean age was $24.7 \pm 5.7 \mathrm{yr}$; most were African American (69\%); single (87\%); $57 \%$ had 2-4 sexual partners previous yr; $44 \%$ had new partners in last 3 months; $32 \%$ were currently having sex $>1$ person; $16 \%$ practiced anal sex in the last 3 months; $13 \%$ never used condoms; $77 \%$ had been treated for an STI; (5 HIV+). In multivariate analysis, repeat IWTK users were more likely to be $\geq 20 \mathrm{yr}$. (OR=2.10, $95 \%$ CI 1.30 to 3.38$)$ and reside in Maryland ( $\mathrm{OR}=2.03,95 \% \mathrm{CI} 1.31$ to 3.13 ). They were more likely to have had a pelvic exam in past yr $(\mathrm{OR}=2.03,95 \%$ CI 1.36 to 3.05); be treated for an STI ( $\mathrm{OR}=2.32,95 \% \mathrm{CI} 1.57$ to 3.44$)$; to perceive internet screening as confidential $(\mathrm{OR}=1.98,95 \% \mathrm{CI} 1.32$ to 2.97); report results from self-administrated swabs as accurate $(\mathrm{OR}=2.49,95 \% \mathrm{CI} 1.61$ to 3.87$)$; be less likely to drink alcohol before sex $(\mathrm{OR}=0.63,95 \% \mathrm{CI} 0.44$ to 0.91$)$; and to never use condoms with vaginal sex ( $\mathrm{OR}=0.43,95 \% \mathrm{CI} 0.27$ to 0.69$)$. Of repeat users, $84.2 \%$ reported having a negative prior test and 48/304 (15.8\%) reported last test positive; 27 had CT; 24 had TV; 3 had GC; 6 were mixed infections. At present test, 40 (13.2\%) were positive: 14 had CT, 2 had GC, 28 had TV; 4 were mixed infections. Previous TV was associated with current TV positivity $(p<0.05)$.

Conclusions IWTK attracted many previous participants who practiced high-risk sexual behaviours to use IWTK for repeat STI testing. IWTK may offer an alternate approach for rescreening previously infected women.

\section{P1-S6.16 AUSTRALIAN CHLAMYDIA CONTROL EFFECTIVENESS PILOT: PRELIMINARY RESULTS FROM A TRIAL OF CHLAMYDIA TESTING IN GENERAL PRACTICE}

\section{doi:10.1136/sextrans-2011-050108.240}

${ }^{1} \mathrm{~J}$ Hocking, ${ }^{1} \mathrm{M}$ Temple-Smith, ${ }^{1} \mathrm{~S}$ Poznanski, ${ }^{2} \mathrm{R}$ Guy, ${ }^{3} \mathrm{~N}$ Low, ${ }^{2} \mathrm{~B}$ Donovan, ${ }^{1} \mathrm{~J}$ Gunn, ${ }^{2} \mathrm{M}$ Law, ${ }^{2} \mathrm{~J}$ Kaldor, ${ }^{1} \mathrm{C}$ Fairley. ${ }^{1}$ University of Melbourne, Carlton, Australia; ${ }^{2}$ University of New South Wales, Australia; ${ }^{3}$ University of Bern, Switzerland

Background While opportunistic chlamydia screening is conducted in several countries, debate remains about the effectiveness of population-based screening programs for reducing chlamydia transmission and its morbidity. The Australian Chlamydia Control Effectiveness Pilot (ACCEPt) aims to assess the feasibility, acceptability, efficacy and cost-effectiveness of annual chlamydia testing in general practice.

Methods ACCEPt is a cluster randomised controlled trial targeting sexually active 16-29-year old women and men for annual chlamydia testing. 54 postcodes (towns) are being randomised and all GP clinics within each area invited to participate. A multifaceted intervention to maximise testing includes: a computer alert prompting GPs to test; incentive payments for GPs and payments for employing practice nurses; a recall system to encourage annual testing; partner notification, and; information/support with regular feedback on testing performance. Clinics in the control group are encouraged to continue their usual practice. The intervention will be in place for up to 4 years. The primary outcome is change in chlamydia prevalence among a consecutive sample of $80-100$ patients attending participating clinics in each postcode (total sample size about 4500) measured at the beginning and end of the trial. Secondary outcomes include pelvic inflammatory disease and chlamydia testing rates.
Results Recruitment began in July 2010 and 282 GPs in 69 clinics in 24 postcodes have been recruited to date in the States of Victoria, New South Wales and Queensland. Four clinics have refused so far and these postcodes have been excluded. To date, 61516 to 29 year olds have been tested during the baseline prevalence survey with a participation rate of $70 \%$. Overall chlamydia prevalence is $4.0 \%$ (95\% CI $2.5 \%$ to $6.0 \%$ ). Prevalence is slightly higher among males (4.5\%; $95 \%$ CI $2.0 \%$ to $8.7 \%$ ) than females $(3.7 \%$; $95 \%$ CI $2.0 \%$ to $6.3 \%, p=0.7)$ and in rural (6.9\%; $95 \%$ CI $3.8 \%$ to $11.2 \%)$ compared with metropolitan areas (2.2\%; 95\% CI $0.9 \%, 4.4 \%, \mathrm{p}<0.01)$. Recruitment will be completed by December 2011 with the intervention period running till end of 2014 .

Conclusions This study shows high participation rates by GP clinics and by individuals invited to take part in the prevalence survey. Results will determine whether annual chlamydia testing is effective at reducing transmission and morbidity and will inform the optimal design of a chlamydia testing program in Australia.

\section{P1-S6.17 OPTING OUT TESTING FOR HIV IN DUTCH STI CLINICS: DOES IT WORK?}

doi:10.1136/sextrans-2011-050108.241

${ }^{1} \mathrm{~F}$ Koedijk, ${ }^{2,3} \mathrm{~J}$ van Bergen, ${ }^{4,5} \mathrm{~N}$ Dukers, ${ }^{4,5} \mathrm{C}$ Hoebe, ${ }^{3,6} \mathrm{M}$ van der Sande, ${ }^{7}$ on behalf of the Dutch STI centres. 'National Institute of Public Health and the Environment, Bilthoven, Netherlands; ${ }^{2}$ STI AIDS Netherlands, Amsterdam, the Netherlands; ${ }^{3}$ Centre for Infectious Diseases and Control, National Institute for Public Health and the Environment, Bilthoven, the Netherlands Netherlands; ${ }^{4}$ Department of Infectious Diseases, Public Health Service South Limburg; ${ }^{5}$ Department of Medical Microbiology, Maastricht University Medical Center, Maastricht, the Netherlands Netherlands; ${ }^{6}$ Academic Medical Centre Utrecht, Utrecht, the Netherlands Netherlands; ${ }^{7} A$ van Daal, $P$ van Leeuwen, F de Groot, A Niekamp, M Langevoort, A van Camerijk, J van de Sande, E van der Veen Netherlands

Background In 2005, STI centres in the Netherlands started provider-initiated HIV testing policy, in order to decrease the proportion of people unaware of their positive HIV status and to enable interruption of transmission and create more opportunities for timely treatment. This policy gradually evolved towards opt-out HIV testing and in January 2010, this became the official policy within all Dutch STI centres. The effects of the change in HIV test policy were studied and factors associated with opting out for HIV testing were identified.

Methods Data from January 2004 to June 2010 from 488727 consultations registered in the Dutch national surveillance in the STI centres were used to characterise current practices on HIV testing. Known HIV positives were excluded from analyses. Logistic regression analyses were done separately for men having sex with men (MSM) and heterosexuals, to identify factors associated with refusing an HIV test.

Results Since 2004, the percentages of HIV testing within an STI consultation have increased significantly from $56 \%$ up to $92 \%$ in 2009 , and further to $97 \%$ in the first half of 2010 when opting out was implemented nationally (both $\mathrm{p}<0.001$ ). STI were significantly more often diagnosed in clients not tested on HIV during their consultation $(p<0.001)$, except in 2010. Using 2010 data, MSM being older than 25 years (OR: 1.8, 95\% CI 1.2-2.6), those having STI symptoms (OR $2.295 \%$ CI 1.7 to 2.8 ) and those with a previous STI (OR: $1.5,95 \%$ CI 1.2 to 2.0 ) more often refused an HIV test. For heterosexuals, having had a previous STI (OR: 1.6, 95\% CI 1.3 to 2.0 ), being female (OR: $1.2,95 \%$ CI 1.0 to 1.4 ) and being younger than 25 years (OR: $1.2,95 \%$ CI 1.0 to 1.4 ) were independent factors associated with refusing an HIV test.

Conclusions Although provider-initiated HIV testing already increased HIV testing rates, national implementation of opting out for HIV testing increased this uptake even more. Standard testing on HIV in every STI clinic is shown to be highly feasible and effective. 
In order to optimise the opt out policy, and thereby successful interruption of HIV transmission, interventions to motivate "optouters" should be studied, since the few clients still refusing an HIV test were linked to higher risk behaviour.

\section{P1-S6.18 CHARACTERISTICS OF MEN WHO SEEK RESCREENING FOR STIS AFTER ONCE USING THE HTTP://WWW.IWANTTHEKIT.ORG SCREENING PROGRAM}

doi:10.1136/sextrans-2011-050108.242

${ }^{1} \mathrm{Y}$ H Hsieh, ${ }^{1} \mathrm{M}$ Barnes, ${ }^{1} \mathrm{M}$ Jett-Goheen, ${ }^{1} \mathrm{~N}$ Quinn, ${ }^{1} \mathrm{P}$ Agreda, ${ }^{2} \mathrm{P}$ Whittle, ${ }^{1} \mathrm{~T}$ Hogan, ${ }^{1} \mathrm{C}$ Gaydos. 'Johns Hopkins University, Baltimore, USA; ${ }^{2}$ Baltimore City Health Department, USA

Background The iwantthekit (IWTK) Internet screening program offered an opportunity to study characteristics of men who seek rescreening, as well as determine reported infected status at the previous screening.

Methods We determined characteristics of male repeat users from questionnaires. Predictors of repeat users were identified in a matched case-control study by conditional logistic regression analysis. A case was defined as reporting ever having used IWTK before. A control was a user who reported never using the program before. Two controls were systematically sampled for each case by matching the date of use IWTK of the case within 3 months.

Results During 2007-2010, 115 (14\%) of 852 men who used IWTK for STI testing, indicated that they had used IWTK previously. Among them, $43 \%$ used it $>2$ times. Mean age was $25.8 \mathrm{yr} \pm 8.5 \mathrm{yr}$, and $90 \%$ were currently sexually active. $17 \%$ reported having sex with a male; $35 \%$ had $>5$ partners in the past yr; $58 \%$ had new partners in last 3 months; $49 \%$ currently were having sex $>1$ person. $63 \%$ had been treated for an STI: chlamydia (CT)(74\%), trichomonas (TV)(42\%) and gonorrhoea (GC)(23\%); 6 reported being treated for HIV. By matching time of enrolment, 230 controls were selected. In the multivariate analysis, repeat IWTK users were more likely to be $<30$ years $(\mathrm{OR}=2.04,95 \% \mathrm{CI} 1.04$ to 4.02$)$, have health insurance $(\mathrm{OR}=2.01,95 \% \mathrm{CI} 1.10$ to 3.69$)$, reported ever being tested for an STI (OR=2.01, 95\% CI 1.02 to 3.97), ever been treated for an STI (OR=2.20, 95\% CI 1.14 to 4.23), particularly TV $(\mathrm{OR}=5.16,95 \%$ CI 1.80 to 14.81$)$, and less likely to have penile discharge currently $(\mathrm{OR}=0.24,95 \%$ CI 0.08 to 0.76$)$. Of male repeaters, $80.9 \%$ reported previous test results from IWTK as negative and 22/115 (19.1\%) reported previous result positive-11 had CT, 4 had GC, 8 had TV; 2 of these were mixed infections. At present test, 24 tested positive -19 had CT, 3 had GC, 5 had TV; 3 were mixed infections. Reported CT positivity in last test was associated with current CT test positivity $(p<0.05)$.

Conclusions The Internet screening program IWTK attracted a number of previous male users of IWTK, who practiced high-risk sexual behaviours, to use the program for repeat STI testing. IWTK provided an alternate approach for rescreening previously infected men as well as men reporting high-risk behaviours.

\section{P1-S6.19 COMPARING TWO METHODS OF ESTIMATING CHLAMYDIA SCREENING COVERAGE IN AN URBAN NEIGHBOURHOOD, 2009}

doi:10.1136/sextrans-2011-050108.243

${ }^{1} \mathrm{M}$ Nelson, ${ }^{2} \mathrm{P}$ Pathela, ${ }^{2} \mathrm{~S}$ Blank, ${ }^{2} \mathrm{~J}$ Schillinger. ${ }^{1}$ Cicatelli Associates, Inc, New York, USA; ${ }^{2}$ New York City Department of Health and Mental Hygiene, New York, USA

Background CDC recommends sexually active females aged $<26$ be screened annually for Chlamydia trachomatis (Ct). Only Ct cases are reported to local health departments. Screening coverage estimates, defined as the proportion of the sexually active population tested for $\mathrm{Ct}$, are not routinely available. Without such measures it is difficult to interpret increases in Ct case reports.

Methods We compared 2 approaches to estimating screening coverage in the New York City neighbourhood of Central Brooklyn (CB) in 2009: The "indirect method" used public health surveillance data, and "back calculated" to get the number of sexually active females that must have been screened to yield the number of reported $\mathrm{Ct}$ cases in CB females aged $15-19$ and 20-25 years. Data inputs included: reported number of females with $\geq 1 \mathrm{Ct}$ case in 2009 (730 cases aged $15-19,619$ cases aged 20-25) population estimates (12 772 aged 15-19, 14024 aged 20-25), proportion ever had sex (35\% aged 15-19), proportion sexually active in last 12 months (76\% aged $20-25)$, and Ct positivity (20\% aged $15-19$, $8 \%$ aged $20-25)$. The "direct method" used electronic health record (EHR) data from 8 primary care provider practices in $\mathrm{CB}$ and adjoining zip codes using a common EHR for $>1$ year. EHR data were analysed to determine: numbers of unduplicated female clients aged 15-19 and 20-25, proportion sexually active, and number of sexually active females screened for Ct. The sexually active population was measured in 2 ways; group 1 was defined as females that reported ever having sex (18\% (246/1340) aged $15-19$ and $12 \%$ (302/2419) aged 20-25). Group 2 was defined as females meeting $>1$ of: reported ever having sex; ever prescribed an oral contraceptive by the practice; ever had an STD; ever diagnosed with STD by the practice; ever pap ordered by the practice (38\% (514/1340) aged 15-19 and 38\% (910/2419) aged 20-25).

Results See Abstract P1-S6.19 table 1.

Abstract P1-S6.19 Table 1 Estimated Chlamydia Screening Coverage for Central Brooklyn Females by Method and Age Group, 2009

\begin{tabular}{llllll}
\hline Method & $\begin{array}{l}\text { Age } \\
\text { group }\end{array}$ & $\begin{array}{l}\text { Female } \\
\text { population }\end{array}$ & $\begin{array}{l}\text { Percent } \\
\text { sexually } \\
\text { active }\end{array}$ & $\begin{array}{l}\text { Number } \\
\text { Ct tested }\end{array}$ & $\begin{array}{l}\text { Estimated } \\
\text { screening } \\
\text { coverage }\end{array}$ \\
\hline Indirect & $15-19$ & 12772 & $35 \%(4406)$ & 3632 & $82 \%$ \\
& $20-25$ & 14024 & $76 \%(10630)$ & 8234 & $77 \%$ \\
EHR & & & & & \\
Group 1 & $15-19$ & 1340 & $18 \%(246)$ & 167 & $68 \%$ \\
& $20-25$ & 2419 & $12 \%(302)$ & 178 & $59 \%$ \\
Group 2 & $15-19$ & 1340 & $38 \%(514)$ & 315 & $61 \%$ \\
& $20-25$ & 2419 & $38 \%(910)$ & 518 & $57 \%$ \\
\hline
\end{tabular}

Conclusion The indirect approach yielded a higher Ct screening coverage estimate than the direct approach. By both methods, screening coverage was higher in the $15-19$ age group than the 20-25 age group. For the direct approach, definitions of sexually active women affected measures of screening coverage, particularly for 15-19 year olds. The indirect method can be easily replicated with limited resources. The direct method requires more resources and is contingent on consistent and accurate provider documentation of sexual activity.

\section{P1-S6.20 PERINATAL SCREENING FOR STIS IN THE USA: ADHERENCE TO PREVENTIVE SCREENING RECOMMENDATIONS FOR HIV AND SYPHILIS AMONG THE COMMERCIALLY INSURED (2008)}

doi:10.1136/sextrans-2011-050108.244

G Janes, A Beard, G Tao, K Hoover, C Kent. Centers for Disease Control and Prevention, Atlanta, USA

Background Perinatal transmission of sexually transmitted infections is a preventable source of morbidity. In the USA, the incidence 